\title{
Introduction: PPPs - theoretical challenges and directions forward
}

\section{W. Richard Scott, Raymond E. Levitt and Michael J. Garvin}

We do not subscribe to a goal of unconstrained development for its own sake; but assuring an adequate supply of civic infrastructure (including housing, roads and public transport, power, water supply and sanitation) is essential to meet the needs of developing countries where populations are growing and becoming more urbanized, as well as those of developed countries where infrastructure is aging and in need of repair and/or replacement. Important as it is, however, providing the necessary infrastructure confronts severe difficulties. Governments of emerging market countries face enormous shortfalls in financial and governance capacity in delivering sorely needed new infrastructure for their growing populations. At the same time, financially strapped governments of mature market economies are struggling to upgrade and retrofit their aging and obsolete infrastructure. Societies at both ends of the development spectrum need more robust project governance structures that can enable new forms of financing coupled with improved systems of managerial oversight and control.

Infrastructure is central to societal welfare, and the high cost of replicating the "last mile of pipe or wire" often requires a monopolistic state provision or regulated private provision strategy. We would thus ordinarily expect that the state would play a major role in its prioritization, funding, development and operation. However, historically this has not always been the case. Specific countries vary in their experience, but the United States (US) is not atypical. As Miller and Floricel (2000) point out, during much of the nineteenth century US transportation systems and power networks were built by private entrepreneurs, with minimal public involvement. Toward the end of the century, large corporate groups replaced the entrepreneurs but still experienced only modest public oversight. However, during the Progressive era of the early twentieth century, private initiatives were increasingly regulated and, over time, nationalized as public 
enterprises. For the greater part of the century, federal, state and local authorities planned, funded, built and operated the bulk of infrastructure. However, during the 1980 s, buoyed by a more conservative political wave, calls intensified for the privatization of these enterprises. From that period to the present, varying combinations of private and public entities have partnered to provide these facilities and services.

In liberal democracies, the public presence typically takes the form of leadership and continuing participation by elected officials, public agencies and varying types of civic associations in the planning and oversight of projects. Private, for-profit firms are viewed as essential to supply private resources and technical know-how in the service of creating, maintaining and operating public facilities. Hence, over roughly the past four decades, governments worldwide have been experimenting with varying types of public-private partnerships (PPPs) which are expected to shape and oversee long-term - for example, 25- to 50-year - concession contracts to finance, design, construct and operate infrastructure projects. Countries and regions vary substantially in their capacity to mount and manage these complex arrangements successfully. Compared to other developed societies that have led the way in constructing supportive national or regional frameworks for PPPs, the US has been relatively slow to adopt these approaches and so stands to benefit from the experience of other countries.

\section{THE NEED FOR INFRASTRUCTURE}

The term "infrastructure" is a broad one, encompassing multiple and diverse elements of the built and natural environment. It is used to encompass such varied features as roads, railroads, rapid transit, ports, airports, power generation and transmission, telecommunications, water supply and waste treatment, dams, and public buildings such as courthouses, schools and hospitals. Each of these sectors poses its own special technical and business challenges. In order to simplify our task, we have chosen to focus our empirical attention on the transportation sector, even though much of our theoretical framework is applicable to a much wider range of infrastructure projects. Even with a more limited set of empirical cases, we will have more than enough complexity with which to contend.

In transportation, as is the case for most infrastructure projects, the demand for new roads and bridges, together with the need to maintain and restore existing systems, greatly exceeds the supply. Among ongoing and recent projects, the record of cost overruns, failure to meet schedules and shortfalls in user demand leading to financial restructuring is not encouraging. 
In mature market economies, much of the infrastructure is several decades old and reaching the end of its useful life. In contrast, in emerging market economies with burgeoning populations, much of the economy is informal and tax collection regimes are often very weak even in the more formal part of the economy, so that the ability of governments to finance and fund infrastructure is severely constrained. Moreover, rapidly increasing urbanization in the twenty-first century is generating huge demands for expanding water, sewer, power and transportation infrastructure, along with social infrastructure services such as housing, schools and hospitals, in cities worldwide. The unmet need for civil and social infrastructure has been estimated by multiple sources as being in the tens of trillions of dollars per year.

At the same time, sovereign funds and pension funds worldwide control as much as $\$ 100$ trillion in assets (Clark et al., 2011), a portion of which could be productively invested in infrastructure. Since the financial crisis of 2007, the real (after inflation) returns that pensions have been able to earn from fixed income securities have been essentially zero or negative, requiring them to seek out higher risk-return investments to meet their actuarially required returns of around 8 percent per year. Investing in infrastructure in their countries has both the direct benefit to the pensions of offering moderate-risk, long-term, inflation-adjusted returns above 8 percent, as well as strengthening the economies of their countries through the direct and indirect economic and social benefits that well-designed, built and maintained infrastructure can provide.

The goal of creating the right kinds of governance both within the pension funds and the infrastructure projects to enable the "golden handshake" between these vast pools of currently underperforming, discretionary capital and the proliferation of sorely needed infrastructure projects worldwide has been a major focus of the Global Projects Center at Stanford University over the past decade and was the impetus for much of the research presented in this book.

\section{GOVERNANCE CHALLENGES}

PPP projects are typically complex, uncertain, one-off, long-lived, multiphased, expensive transactions involving a large and shifting number of internal and external stakeholders operating within ever-changing contexts. Let us unpack this dense description.

Project complexity begins with the number and types of tasks that must be performed to accomplish the objective. Campbell $(1988,43)$ proposes that "any objective task characteristic that implies an increase in 
information load, information diversity, or rate of information change can be considered a contributor to complexity." Complexity is increased by the presence of: (1) multiple desired goals; (2) diverse potential ways or paths to arrive at the objective; (3) conflicting interdependence among paths; and (4) uncertain links among paths and outcomes (Campbell, 1988). Focusing attention more on the problems of task coordination, Thompson (1967) emphasized attending to the different degrees and types of interdependence in the project workflows. They might reflect simple pooled interdependence, when each task or subtask independently contributes to the desired outcome. More complexity is imposed by sequentially interdependent tasks, in which one task cannot be undertaken until another has been completed. Even higher levels of complexity attend the presence of reciprocally interdependent tasks, which require mutual adjustment among actors who must align or reconcile their subgoals and activities with those of others as the work proceeds.

Levitt (2015) points out that reciprocal interdependence may assume two guises: compatible and contentious. In the former case, workers find that the subgoals governing their performance are aligned, whereas in the latter case they are conflicting. In general, increased complexity of the tasks being undertaken and increased interdependence of the project workflows particularly, reciprocal contentious interdependence - creates increased demands on the managerial systems required to coordinate the workflows. Contentious interdependence is more likely when multinational firms are involved, when multiple jurisdictions are affected (for example, crosscounty, cross-state), and when competing civic interests become activated. Highway projects also vary substantially in their technical complexity, depending on the nature of the terrain to be traversed, their elevation, the number of barriers (for example, rivers, mountains, other infrastructure) to be crossed, and the types and volume of traffic to be accommodated.

Technical uncertainty relates primarily to the inexact or unknown means-ends connections linking activities to their consequences (March and Simon, 1958). That is, projects vary in the extent to which the technologies are routine, familiar and time-tested or are more experimental and variable in their outcomes. The use of experimental or untested technical processes is not common on transportation projects but may occur on selected components such as bridges or tunnels. Uncertainty is far more likely to be associated with some aspects of the project organization, such as stakeholder composition and/or behavior, and the project's context, such as uncertain political and institutional conditions, as discussed below.

PPP projects are one-offs, in the sense that most project organizations are constructed de novo to construct a particular link in the transportation system; for example, a road from point A to point B. The developers, 
or some other agency with the proper authority, selects a lead company which then creates a special purpose vehicle (SPV) that serves as the focal organization of a unique network of participating organizations, including the public sponsor, financial backers, contractors, operators, clients, regulators, and affected parties such as users and broader publics. The fact that each project begins anew, often with different combinations of participants, means that projects are importantly "learning disabled": unable to carry forward the "lessons learned" from one project to the next. This liability is one reason why the existence of broader, "enabling" support structures at the state or regional level is often critical to the success of PPPs.

Infrastructure projects are relatively long-lived, their development and construction period typically extending over several years and their operation and maintenance over several decades. Because of their associated complexity and uncertainty, Miller and Olleros (2000) argue that the more successful projects are preceded by a long "shaping" period. Even if the technical problems are modest and the outcomes sought are known, it is important for the SPV to consider possible future problems, including how to set up governance arrangements to insure flexibility among team members and anticipate potential changes in key contextual elements, and how to build coalitions that create "buy-ins" among stakeholders.

Projects, of necessity, are multi-phased, passing from a period of exploration and project conception through project financing and shaping, followed by a combined period of design and construction, leading into one of maintenance and operation. It is obvious that these phases require differing talents and activities, so that it should not be a surprise that a project involves a changing collection of stakeholders as it proceeds from earlier to later stages. The coming and going of a varied set of participants also entails changes over time in the relative power of project participants. As might be expected, this condition poses severe challenges to project governance as when, for example, earlier participants' parties make binding decisions that negatively affect later, not yet represented, parties.

Financing of infrastructure projects poses yet another type of challenge. Through the period of public monopoly, the financing of projects was via some type of taxation regime at one or more levels: municipalities, counties, special taxing entities such as school districts or port authorities, states or the federal government. Monies were raised by general taxes but also by the sale of tax-exempt bonds, allowing the financing of public works projects at reduced interest rates. Their tax-exempt nature, however, costs public agencies because of the foregone taxes they would normally collect. The increasing resistance of taxpayers to any increase in taxes together with the international financial crisis of 2007-2008 has encouraged more and more government entities to explore the availability of private 
financing: partnering with private entities that control or can leverage private resources. Promising sources of private capital being cultivated are institutional investors (for example, pension funds and sovereign wealth funds) that control "patient capital" which would seem to be ideal for investing in long-term infrastructure projects. However, to mobilize these resources, institutional investors must acquire new capacities and devise new governance arrangements if they are to fully engage in and benefit from these collaborations.

Stakeholders include all those who are involved in and affected by the organization and operation of the project group. The stakeholders involved in infrastructure projects are likely to be a very large and diverse collection of interested parties. They range from "internal" stakeholders, for example, financial agents, stockholders, managers, other employees and contractual partners, to "external" stakeholders including "all of those groups and individuals that can affect, or are affected by, the accomplishment of [the firm's] organizational purpose" (Freeman, 1984, 25). Included would be such groups as the project's exchange partners, government regulators, consumers, affected communities and interested associations.

Infrastructure projects are also likely to entail efforts of long-term duration, with the completed objects - for example, bridges, rail and highway systems - being expected to be capable of use extending over many decades. Such longevity in itself, however, is not unusual. Government agencies and corporations are also likely to operate for many years. What is unusual is the extent to which the types of stakeholders associated with a project shift over time. Some stakeholders, such as developers, are heavily engaged during early phases and are highly influential, but their centrality wanes over time. Later stakeholders, such as project operators, user groups and various civic movements, become much more active and involved over time. The diverse and shifting nature of stakeholders poses daunting challenges to those designing governance systems.

"Context" is a general, non-specific term referring vaguely to "everything outside the specific unit or system being studied." The problem is, as many project managers have learned to their sorrow, many seemingly benign conditions formally outside of the system being managed can suddenly and unexpectedly change, substantially affecting the performance of the system for which they are responsible. Many types of contextual factors can affect infrastructure projects, ranging from physical and natural forces to market and economic, political, and the social and institutional. Because infrastructure projects are, by their nature, grounded in the physical environment, they are highly susceptible to such forces as earthquakes, fires, floods and severe storms. Tunnels or bridges may encounter unexpected geophysical conditions or hazards (Lessard and Miller, 2000). 
Economic factors include more localized events such as miscalculation or fluctuation in the demand for the facility, to more macro incidents such as economic turndowns or financial crises. Political considerations are particularly salient to PPP projects, because one of the core parties is a government entity. Hence, such projects may become hostage to election cycles, political currents or social protests. Unexpected shortcomings or delays, or the outbreak of real or apparent conflicts of interest, may occasion intense media scrutiny. Social and institutional risks are substantial and can vary over the project phase. Among these are the many legal and regulatory provisions affecting infrastructure; normative elements, which include the varied types of professional standards that govern the work of lawyers, engineers and the various craft occupations engaged in the project; and the cultural assumptions and belief systems associated with private firms, public agencies and/or those associated with varying regions and participant groups (Scott et al., 2011).

In sum, the challenges and risks faced by PPP projects are substantial, varying by nature and location of project as well as by phase of development. Effectively confronting their technical, financial, political and institutional complexity calls for robust and resilient governance structures. The diversity and range of challenges posed have forced parties tasked with addressing them to seek help from an ever-widening range of scholarly fields. In the following section, we provide a brief overview of the major sets of ideas upon which project participants and scholars draw.

\section{RELEVANT THEORETICAL FRAMEWORKS}

We begin with a review of related concepts from organization theory and design.

\section{Organization Theory and Design}

Scholars studying organizations have long emphasized the ways in which the nature of the work performed - its complexity, uncertainty and interdependence - shapes the kinds of structures designed to cope with it. Different kinds of workflows for tasks that span the boundaries of individuals, teams or firms responsible for their execution require different types of coordination mechanisms. Thompson (1967) usefully identifies three types of workflows:

- The work can be such that workers carry out the work independently but, in aggregate, contribute to an overall outcome. This type of 
work creates pooled interdependence, which managers can coordinate by specifying the types of work required and the necessary skills for workers.

- The work can be divided into various tasks to be performed independently by work units, but to be successful the tasks must be performed in a specific order. Such sequential interdependence is coordinated by schedules and by the use of some "buffering" mechanisms to smooth out the workflow.

- The work may require separate work units to take into account the work of others, because the work of each unit serves as both input and output for that of another. Such reciprocal independence requires mutual adjustment among the work units as the work proceeds and, hence, more delegation of discretion to the work units.

As noted earlier, Levitt (2015) suggests that reciprocal interdependence arises in two forms, requiring different mechanisms of coordination. He proposes that we distinguish "compatible" reciprocal interdependence, when conflicting subgoals do not appear during work exchanges, from "contentious" interdependence, when such conflicts do emerge. Contentious interdependence can sometimes be resolved by negotiation between the participants, but often end in deadlocks that require escalation and managerial intervention.

The larger message of this stream of work is that organizational complexity is a response to the complexity of the work involved: managerial frameworks reflect the nature of the work being controlled. This "contingency" framework to organizational structure developed over several decades of productive research (see Galbraith, 1973; Lawrence, 1993; Lawrence and Lorsch, 1967; Thompson, 1967; Burton and Obel, 2004), and has gradually been extended to incorporate the demands associated with managing non-technical aspects of work, including political and cultural factors (Scott and Davis, 2007).

\section{Transaction Cost Economics}

In an early seminal paper, Coase (1937) asked his fellow economists how they were to explain the existence of firms if market forces were thought to be the most effective way to insure the efficiency of exchanges. Nearly a half century later, Williamson $(1975,1985)$ proposed that firms exist because many types of exchange are difficult to negotiate: the processes involved in producing the good or service are complex or uncertain, or the parties involved may be untrustworthy and prone to "opportunism." $\mathrm{He}$ argued that firms emerged that served to erect boundaries to contain that 
subset of exchanges which exhibit high levels of complexity, uncertainty or opportunism. Within these boundaries, firms create hierarchical controls over exchange contracts which allow managers to: (1) provide appropriate information and resources to targeted employees; (2) create auditing and authority systems to exercise necessary controls; and (3) design incentive systems to encourage cooperation.

In general, then, the contracting negotiations which occur within "free" markets are not costless. There are always the questions of: Who can deliver? Who can predict? Who can you trust? The costs of managing exchanges are labeled "transaction costs." When they become sufficiently large, they justify the costs entailed in creating a hierarchy (organization) to oversee them; a hierarchy which itself is costly.

Some recurring transactions have high "asset specificity" - where one or both parties to the transaction can incur expenses that have no value outside of the given transaction if it fails, making them especially prone to opportunistic "hold-up" by the counterparty. For such transactions Williamson proposes that "relational contracting" approaches (versus classical, transactional contracting) supported by third-party mediators will be the optimal governance structure. PPP transactions fit this situation with their long durations, vulnerability to outside forces beyond either parties' control, and dynamic sets of stakeholders.

Of course, there is not one but many types of hierarchy or organization structure (Williamson, 1985). Analysts are encouraged to compare and contrast the varying modes of organizing within contemporary economies, from the simple unitary structure to the more complex multi-divisional and matrix structures to the decentralized network, such as the project-based form, within which the network of contracts can be used to recreate key elements of hierarchy (Stinchcombe, 1985). From the transaction cost perspective, the relational project form of governance is one mode of centralized control that has arisen to police and protect certain classes of complex contracts; and the PPP form is one variant of this structural design (Henisz et al., 2012).

\section{Public Administration}

The examination of public organizations and institutions emerged from the work of historical institutional scholars who compared various instances of governmental forms over time and space. One of the most imaginative was De Tocqueville (1835/2004; 1856/1998, 2001), who compared French and American political systems during pre- and post-revolutionary periods; and others such as Burgess (1902), who focused on differences among Western nations as reflected in their constitutional systems. Indeed, 
most of this early comparative work concentrated on "configurative descriptions" of formal institutions including "constitutions, cabinets, parliaments, courts and bureaucracies" (Bill and Hardgrave, 1981).

During the middle of the twentieth century, this early focus on institutionalized structures was largely supplanted by a behavioral approach, which diverted attention from political systems to political behavior; for example, voting, lobbying, decision-making. While much of this work has been informative and instructive, over time the pendulum has begun to swing back to incorporate structural elements, in part because they have been shown to effect behavior. Thus, Simon (1945/1997) and March and Simon (1958) examined the ways in which administrative structures affected - supported and constrained - the decisions made by their individual participants. Even social movement organizations, such as the women's suffrage struggle, have been shown to rely heavily on pre-existing political forms and recurring repertories of routines (Clemens, 1997).

More recently, investigators have given more attention to the distinctive features of public organizations; to the ways in which they differ from private, market-driven organizations. Scholars from Downs (1967) to Wilson (1989) to Rainey (1991) have pointed out that the goals pursued by public organizations are more diffuse, ambiguous and conflicting then those of private organizations. Whereas private organizations are engaged in making a profit, public systems are expected to serve the public interest, where controversy surrounds the relative importance to be placed on equity and distributional fairness versus independence and freedom of choice. They also are expected to oversee and regulate private organizations, dealing with issues of information asymmetries between firms and clients and externalities, costs created by firms but borne by publics; again, complex, diffuse matters concerning which it is difficult to evaluate outcomes. Because of the ambiguity of goals pursued, government agencies are more likely to be governed by their adherence to processes rather than by assessment of outcomes. They are expected to focus on following established rules, procedures, norms and expectations (Downs, 1967; Wilson, 1989). Most lack profit-maximization incentives, are less attuned to concerns regarding appropriate resource allocation, and lack internal organizational goal alignment.

As explicated by Hult and Walcott (1990), the process values emphasized by public organizations include: (1) structured rationality - processes intended to insure that relevant expertise and information are incorporated into decision-making routines; (2) accountability - procedures to insure that governing officials are held responsible for their decisions and actions; (3) representativeness - procedures to allow those affected by the policies pursued to participate in the shaping of those policies; and 
(4) legitimacy - the belief among the relevant publics that a given policy decision has been formulated in acceptable ways and implemented without undue favoritism. Largely because of the work of institutional scholars (DiMaggio and Powell, 1983; Meyer and Rowan, 1977) there is increased recognition of the importance of legitimacy in insuring the stability and support for all organizations, but especially public organizations.

The principal lesson to be learned from this body of work for those interested in PPPs is a heightened awareness of the differences obtaining between public agencies and private firms. These two organizational forms operate in decidedly different institutional contexts: they are subject to different modes of rationality, different "logics" of action and, for this reason, pose severe governance challenges to those who try to combine them into a single, meta-organizational entity.

\section{Stakeholder Approaches}

Attention to "stakeholders" began to take hold in the late 1970s and 1980s in reaction to the focus by some economists on shareholders as the central players in a rational theory of the firm. Economists such as Friedman (1970), argued that "rational" managers were those who adopted the maximization of return-on-value for shareholders as the touchstone of their decision criteria. To focus on other interests, such as those of workers or the general public, was "to preach pure and unadulterated socialism." The only "social responsibility" of business was "to use its resources and engage in activities designed to increase its profits" within the "rules of the game."

In reaction, other scholars adopted a more inclusive view of the varied groups having a legitimate interest - a "stake" - in the activities of private corporations. Such groups included, but were not limited to, employees, customers, suppliers and members of the community within which the organization was located. Arguments developed ranged from the empirical - corporations do respond to the interests of these groups; to the normative - corporations should respond to the interests of these groups (Freeman, 1984; Laplume et al., 2008; Mitchell et al., 1997). The empirical arguments were bolstered by reigning views within the organizational studies community that organizations were, by their nature, "open" systems, affected by and dependent on interactions with a variety of external groups (Scott and Davis, 2007, Ch. 4). And they were strengthened and informed by developments within network circles that created multiple measures of degrees and types of connectedness - for example, centrality, clustering, equivalence and density - between individuals and/or organizations (see Burt, 1980; Barnes, 1972; Smith-Doerr and Powell, 2005). Such measures 
allowed researchers to assess the extent and strength of connections between varying types of actors, both those formally included within the boundaries of firms or projects, and others technically outside.

Some researchers (see, e.g., Freeman, 1984) propose a simpler, "ego network" approach that focuses on those groups having a direct tie to the organizational unit of interest. More complex approaches attempt to map the overall network, which include all actors and relationships within a given domain or, given this broader topography, examine the network position or location of the various players (Burt, 1980; Kilduff and Tsai, 2003). Measures such as distance - the length of the shortest path between two actors; centrality - how many direct contacts a given actor has with others; or clustering - which examines how connected or cohesive neighbors are within a network, have been usefully deployed.

As noted above, because PPP infrastructure projects are likely to extend over several decades, the numbers and types of stakeholders involved change dramatically over time. So also does their degree of power or centrality in the network (Smith-Doerr and Powell, 2005). For example, design and development teams having great influence in stage one may no longer be active participants in the operational stage; and social movement groups that may not have existed when the project began may become prominent players in defending the interests of client or community groups when the project is up and running. Designing a governance system which will incorporate and accommodate such changes is clearly a challenging task.

\section{Finance Theory}

While economists such as Samuelson (1948), Friedman (1953) and Schumpeter (1954) had explored aspects of finance within economic systems, foundations of contemporary finance theory, in many respects, were established by Markowitz (1952) and Modigliani and Miller (1958). Markowitz's ideas about portfolios and risk versus return mobilized a series of studies that are the basis of theory and practice about investments and portfolio management to the present day. Alternatively, the theorems of Modigliani and Miller are at the heart of contemporary analyses of capital structure. In particular, their "irrelevance" proposition, that financing decisions do not affect firm value under specific conditions, has fueled contemplation of circumstances where financial structure does matter.

Nowhere are such considerations given more attention than in the financing of large infrastructure projects, such as PPPs, which has become fertile ground for studying the implications of financial architectures. Brealey et al. (2000) explained that reallocating project cash flows and risks among various participants in well-functioning markets does not typically 
create value or lower the cost of capital; however, financing choices can influence value and the cost of capital particularly when they enhance project performance and management through improving incentives. Indeed, the discipline and practice of project finance are largely premised on identifying those aspects of project structure that impact managerial incentives to generate value and manage risk (Esty, 2004). Not surprisingly, it is the dominant financing strategy for PPPs, since project finance can transfer risks to debt holders and contractors who can bear the risks at a lower cost or manage specific activities more expertly and efficiently.

Hence, realizing such advantages in PPPs - to the potential dismay of governments simply seeking a convenient avenue to move assets off their balance sheet - means far more than assembling private sources of money. It entails careful consideration of the network of stakeholders involved to allocate risks to those holding a comparative advantage, and to configure incentives for each to respond productively to diverse events over time (Brealey et al., 2000). Put more simply, the legitimacy of the prevailing PPP financial structure depends on good project governance.

\section{STRUCTURE OF THIS VOLUME}

Although this is an edited volume, the following chapters reflect a common perspective in the sense that all contributors draw on a broadly shared conceptual framework. More specifically, all of the contributors have ties to the Global Project Center (GPC) at Stanford University. The GPC has served as the focus of a broad "collaboratory" which, over its more than 16-year history, has attracted scholars from around the world to pursue research reflecting a broadly similar agenda. While there exists general agreement within the GPC community on the need to improve infrastructure project finance and governance, our contributors vary in their disciplinary background, on the specific focus of their scholarship, and in their choice of context for gathering data. Some of the assembled chapters have not previously been published, while others have appeared in a variety of venues. Most of them have been extensively edited for the purposes of this volume.

The chapters included in Part I describe the defining features of PPPs, consider their development and variants, and depict some of the common misconceptions or myths which have confounded them over the years. Also, they examine the continuing fundamental differences between public and private organizations; differences which underpin the difficulties that arise in combining them. The chapters of Part II deal with the multiple types of challenges confronting the design of governance structures for 
PPPs as they progress through planning, design, construction, operations and maintenance phases of their life cycle. Part III focuses on the varied sources of private and public financing for PPPs, the difficulties associated with aligning the goals of private investors and public agencies, and mechanisms employed to distribute financial risk among the various parties and to govern them in the public interest. Part IV explores the potential for fostering the development of regional and national systems that have demonstrated, in some contexts, the potential for strengthening and enabling the performance of PPP projects, and their current levels of institutional maturity in different countries. And Part V describes two innovative project delivery approaches that are evolving for financing and delivering large versus small infrastructure projects: one top-down, and the other bottom-up. 